\title{
AUDITORIA CONTÍNUA: UMA PESQUISA-AÇÃO RETROSPECTIVA
}

\author{
Carlos Henrique Pereira Mello \\ Luiz Gonzaga Mariano de Souza² \\ João Batista Turrioni \\ Danielle Fernandes Campos ${ }^{4}$
}

\begin{abstract}
Resumo: Este trabalho apresenta a proposta de uma ferramenta, denominada auditoria contínua, cujo objetivo é melhorar o processo de auditoria interna através do registro das não-conformidades de um sistema de gestão da qualidade (SGQ) voltado para a norma ISO 9001 em tempo real e aumentar a participação dos colaboradores da organização no processo de avaliação do SGQ. Esta ferramenta foi desenvolvida a partir da combinação das ferramentas de gestão visual, CEDAC e auditoria da qualidade. Através de uma pesquisaação retrospectiva é relatada uma pesquisa desenvolvida há 10 anos em uma empresa de produtos térmicos, que resultou em uma dissertação de mestrado. A verificação da adequação da ferramenta proposta pela pesquisa mostrou que houve uma redução do número de não-conformidades dos requisitos analisados. A pesquisa permitiu concluir que a ferramenta proposta propicia uma maior participação dos colaboradores na avaliação e melhoria do SGQ e que a mesma contempla as características de um instrumento de comunicação baseado em gestão visual.
\end{abstract}

Palavras-chave: Sistema de gestão da qualidade; gestão visual; pesquisa-ação retrospectiva.

\begin{abstract}
This work proposes a tool, called continuous audit, whose objective is to improve the internal audit process through the registration of the quality management system (QMS) nonconformities based in ISO 9001 standard in real time and to increase the employees' participation in the process of QMS evaluation. This tool was developed starting from the combination among visual management, CEDAC and quality audit. This work relates, through a retrospective action-research in a thermal products company, a research made 10 years ago that results in a dissertation. The verification of its adequateness shows that a reduction of the number of nonconformities of the analyzed requirements was obtained. The research allowed concluding that the proposal tool support a larger employees' participation in the evaluation and improvement of QMS and that it beholds the features of a communication instrument based on visual management.
\end{abstract}

Keywords: quality management system;Visual management; Retrospective action-research.

1 Universidade Federal de Itajubá (UNIFEI). Professor Adjunto do Instituto de Engenharia de Produção e Gestão (IEPG). E-mail: carlos.mello@unifei.edu.br

2 Universidade Federal de Itajubá (UNIFEI). Professor Titular do Instituto de Engenharia de Produção e Gestão (IEPG). E-mail: gonzaga@unifei.edu.br

3 Universidade Federal de Itajubá (UNIFEI). Professor Adjunto do Instituto de Engenharia de Produção e Gestão (IEPG). E-mail: 4058@unifei.edu.br

4 Universidade Federal de Itajubá (UNIFEI). Mestre em Ciências em Engenharia de Produção do Programa de Pós-graduação da UNIFEI. E-mail: dfc.unifei.2008@gmail.com 


\section{INTRODUÇÃO}

O presente trabalho relata uma pesquisa retrospectiva de um projeto de pesquisa-ação, planejado e realizado há 10 anos atrás. Seu objetivo era propor uma ferramenta com apelo visual para aumentar a participação dos colaboradores nos processos de auditoria interna dos sistemas de gestão das organizaçóes. Nos processos convencionais de auditoria, tal como ocorrem nos sistemas de gestão da qualidade e ambiental, os auditados geralmente adotam posições de defesa em relação aos auditores, prejudicando a avaliação de seus processos.

Um cenário similar ocorreu com a inspeção da qualidade dos produtos. Sullivan (1986) destaca sete estágios pelos quais a qualidade evoluiu. Desses sete estágios, os três primeiros são importantes para se fazer uma analogia entre o que se apresenta neste estudo e a evolução da gestão da qualidade. São eles: a inspeção após a produção (orientada para o produto), a inspeção durante a produção (orientada para o processo) e a garantia da qualidade envolvendo todos os departamentos (orientada para o sistema).

Com o primeiro estágio, a qualidade não é melhorada e ela se torna uma simples correção de defeitos, não lidando com as anormalidades do processo, uma vez que a inspeção é realizada por inspetores independentes. Já no terceiro estágio, a ênfase é dada em se mudar o sistema para melhorar a qualidade. Nesse estágio tem-se a abordagem inicial para a qualidade total e a inspeção da produção ocorre na forma do autocontrole do processo, feito pelos próprios funcionários da produção.

Essa evolução mostra que a inspeção da qualidade passou por algumas mudanças significativas, quanto à responsabilidade pela inspeção. Da mesma forma que para o primeiro estágio evolucionário do processo de inspeção, o processo de auditoria de sistemas de gestão requer que os auditores sejam independentes das áreas a serem auditadas. Dessa forma, obtém-se uma baixa contribuição dos auditados no processo. Eles poderiam colaborar e participar mais ativamente nessas atividades de melhoria do seu processo de trabalho se existisse uma ferramenta que os motivassem para tal.

Além disso, o processo de auditoria de sistemas de gestão convencional apresenta as seguintes limitações: (1) o fator tempo, uma vez que as não- -conformidades nem sempre acontecem durante a realização da auditoria; (2) o fator amostragem, que pode fazer com que as oportunidades de melhorias do sistema não sejam evidenciadas por possíveis falhas nesse quesito; (3) a pouca participação do auditado durante a realização das auditorias, muitas vezes atuando de maneira defensiva e ocultando as deficiências não aparentes aos auditores; e (4) a necessidade de independência dos auditores, que faz com que as pessoas com maior conhecimento sobre uma dada área ou setor não participem da auditoria.

Muitos desses problemas identificados no processo de auditoria ainda são tratados na última década. Kaziliûnas (2008) comenta que as auditorias geralmente não fornecem dados para tomadas de decisões gerenciais a respeito de desenvolvimento de pessoas, tecnologia, crescimento, produto e processos porque essas decisões são baseadas no desempenho atual e, frequentemente, toda a auditoria revela a conformidade atual, ou seja, não aquela que acontece no dia a dia da organização. Terziovski, Power e Sohal (2002) concluem que auditoria de conformidade predomina nos estágios iniciais de implementação do sistema da qualidade. No entanto, a sua eficácia diminui quando o sistema da qualidade amadurece.

Sendo assim, O’Hanlon (2003) afirma que uma mudança de paradigma é necessária. Os métodos de auditoria não podem se concentrar somente na conformidade; a ênfase da auditoria deveria estar na genuína melhoria, alinhada com os objetivos de negócio, não em não conformidades triviais. Os auditores deveriam gastar menos tempo examinando como as coisas são feitas e mais tempo buscando compreender porque elas são feitas e como são integradas com outros processos do negócio. Recentemente, Souza, Faria Neto e Muniz (2009) trataram dessas questões no setor aeroespacial.

Para tentar sanar essas limitações, o presente trabalho tem por objetivo principal propor uma ferramenta capaz de contribuir com o processo de manutenção e melhoria contínua de um sistema de gestão da qualidade, no sentido de atender aos seguintes objetivos específicos: proporcionar um instrumento para registro das não-conformidades do sistema de gestão da qualidade em tempo real; aumentar a participação dos funcionários na melhoria dos padrôes da empresa; e contribuir na redução do número de não-conformidades do sis- 
tema de gestão da qualidade. A ferramenta a ser proposta e estudada por este trabalho será denominada de auditoria contínua.

$\mathrm{Na}$ época do planejamento e realização da pesquisa, a mesma foi publicada apenas na forma de uma dissertação de mestrado, o que limita sua disponibilidade para outros pesquisadores. Em virtude disso, esse trabalho espera contribuir com a base de conhecimento da gestão da qualidade ao apresentar a ferramenta proposta para a comunidade científica e, além disso, discutir os aspectos relevantes para o relato de uma pesquisa retrospectiva, por meio do método da pesquisa-ação. Considera-se que a ferramenta proposta, cujo ponto forte é a disseminação e socialização da informação à respeito da qualidade da gestão, seja útil até os dias de hoje para as empresas que desejem aumentar a participação de seus colaboradores na melhoria de seu sistema de gestão da qualidade.

Metodologicamente, inicialmente o presente trabalho é de cunho conceitual-teórico, tal como preconizado por Filippini (1997), para o mapeamento da literatura a respeito de auditorias da qualidade, ferramentas para apoiar o processo de solução de problemas e gestão visual, proporcionando a integração destas em uma ferramenta para fomentar a manutenção e melhoria do sistema de gestão da qualidade dos diversos setores de uma organização, à partir do trabalho participativo dos próprios funcionários desses setores.

A verificação da adequação da ferramenta proposta em atender aos objetivos desta pesquisa foi realizada através de uma pesquisa-ação, realizada entre 1996 e 1997, durante o processo de implantação do sistema de gestão da qualidade em uma empresa do ramo de produtos térmicos, selecionada como unidade de análise, onde um dos autores do presente trabalho atuava como coordenador da qualidade. $\mathrm{O}$ roteiro para pesquisa-ação adotada naquela época foi a proposta por Thiollent (1996). O presente relato será realizado por meio de uma pesquisa-ação retrospectiva, tal como já publicado em outros trabalhos (BALLANTYNE, 2004; BALLANTYNE, 2003; BALLANTYNE, 2000). Além disso, a pesquisa-ação retrospectiva é considerada uma abordagem metodologicamente aceita por Coughlan e Coghlan (2002). Essa seria uma outra contribuição do presente trabalho, ao apresentar as condiçôes necessárias para a realização de uma pesquisa-ação retrospectiva, ainda pouco explorada na literatura.

\section{REVISÃO DE LITERATURA}

\subsection{AUDITORIAS DA QUALIDADE}

As auditorias de sistemas da qualidade são feitas, segundo Mills (1994), com dois propósitos básicos: adequar a documentação do sistema da qualidade em relação a uma norma de referência e verificar a conformidade das operações internas da empresa em relação ao sistema da qualidade implantado.

Esses propósitos podem ser atingidos através de três tipos de auditorias: primeira parte (ou interna), segunda parte (ou de fornecedores) ou terceira parte (avaliação externa independente).

A proposta deste trabalho está voltada para as auditorias de primeira parte em relação a um sistema da qualidade com base na norma NBR ISO 9001. A auditoria interna da qualidade é uma ferramenta que a norma ISO 9001 dispóe e que deve ser utilizada com o objetivo de avaliar ou verificar a adequação das atividades relacionadas com a qualidade. Se bem conduzida, a auditoria interna se constitui de um processo positivo e construtivo. Ela auxilia a empresa a manter e melhorar o seu sistema da qualidade através da identificação de atividades com potencial para criar problemas futuros. Esses problemas são oriundos da ineficiência ou inadequação das atividades em questão.

A norma NBR ISO 9000 define a auditoria como um processo sistemático, documentado e independente, para obter evidência da auditoria e avaliá-la objetivamente para determinar a extensão na qual os critérios de auditoria são atendidos. As evidências da auditoria são registros, apresentação de fatos ou outras informações, pertinentes aos critérios de auditoria que sejam verificáveis. Os critérios de uma auditoria são formados pelo conjunto de políticas, procedimentos ou requisitos que são usados como uma referência e contra os quais são comparadas as evidências da auditoria (ASSOCIAÇÃO BRASILEIRA DE NORMAS TÉCNICAS, 2005). Paxton et al. (2006) complementam que o propósito principal da auditoria é aperfeiçoar a qualidade do sistema por meio da aderência aos padróes.

Karapetrovic e Willborn (2000) afirmam que os auditores devem ser livres de tendências e influências que possam afetar a objetividade da auditoria, devendo os mesmos, no caso de uma auditoria interna, não terem nenhuma responsabi- 
lidade direta pela área a ser auditada. Esse aspecto é realmente válido para garantir a imparcialidade desse processo e atender aos requisitos da norma ISO 9001. Entretanto, a necessidade de pessoas independentes da área a ser auditada pode trazer uma dificuldade para se alocar profissionais com conhecimento suficiente sobre um departamento ou processo específico para uma auditoria. Afinal, as pessoas que detém um maior conhecimento a respeito de um processo chave da empresa são justamente aquelas que o vivenciam no seu dia-a-dia. O processo convencional de auditoria torna essas pessoas impossibilitadas de auditar seus próprios processos. A contribuição desses profissionais com o sistema da qualidade muitas vezes se dá através da utilização do processo de ação corretiva ou preventiva que, em geral, é reativo e não promove a integração das pessoas com o sistema da qualidade e nem o processo de aprendizagem organizacional, uma vez que esses funcionários, geralmente, preenchem um formulário de ação corretiva ou preventiva somente quando instigados por um representante da área da qualidade.

Dessa forma, muitos funcionários que não fazem parte do grupo de auditores da empresa podem se sentir desprestigiados, ocasionando o seu distanciamento do sistema de gestão da qualidade. Uma possível forma de mudar este panorama é fazer com que o processo de avaliação do sistema de gestão seja mais participativo, com o apoio de ferramentas da gestão visual.

\subsection{GESTÃO VISUAL}

Gestão visual é uma forma de comunicação que pode ser observada por qualquer um que trabalha em uma dada área, qualquer um que esteja de passagem por esta área e para qualquer um onde a informação esteja visível. Ou seja, é aquela comunicação que está disponível em uma linguagem acessível para todos aqueles que possam vê-la, trazendo uma nova luz e uma nova vida à cultura no local de trabalho, através do compartilhamento das informações.

Para Ranky (2007), a gestão visual significa dispositivos visuais de informação simples, contudo, eficientes, que incluem sinalizaçōes, gráficos, figuras ilustrativas dos processos, máquinas e estaçôes de trabalho com sinalizadores coloridos, placares etc. Em um nível avançado, a gestão visual desenvolve sistemas de apoio multimídia interativos em tempo real para fazer com que todos os funcionários estejam cientes de como a fábrica está operando.

Hall (1987) define a comunicação visual como uma comunicação sem palavras, sem voz, não apenas das condições do nível operacional, mas sendo um verdadeiro mapa das condiçóes da empresa para todos aqueles que podem ler sinais físicos. Para ele, a proposta da visibilidade que a gestão visual oferece é o efetivo e imediato feedback.

Mestre et al. (1999) consideram que a comunicação visual deve ser utilizada livremente. Ela pode estar relacionada a, pelo menos, quatro adjetivos fundamentais: universal, significativa, subliminar e acessível.

Durmusoglu e Kulak (2008) consideram que um computador é uma ferramenta poderosa para a comunicação individual, mas não para uma boa comunicação coletiva. Falta-lhe uma interface pública. Um mural oferece a um grupo de pessoas conhecimento, visibilidade e a oportunidade de atuar como um time. Esse mural pode ser atualizado com todo tipo de informação pelos próprios integrantes desse time.

Segundo Greif (1991), a presença física da informação é insubstituível para o processo de cobrir responsabilidades na área de trabalho. Uma responsabilidade participativa para a informação é observada quando diversos membros de uma empresa se encontram em frente a um mural. O território visual deve ser uma área capaz de proporcionar uma interação intensiva, isto porque as mensagens visuais devem ser sempre direcionadas para a comunicação interna e externa ao território. Isso significa que as mensagens (gráficos, painéis, murais etc.) dispostas em um dado local, têm que ser importantes para os funcionários daquela área de trabalho e para o restante da empresa. O território visual é, acima de tudo, um local de encontro.

Esse local de encontro assume a condição de ser uma área de comunicação. A criação desta área de comunicação busca atender a dois objetivos:

a) facilitar o trabalho da equipe, uma vez que todas as mensagens pertencentes ao grupo encontram-se num mesmo lugar;

b) reforçar as novas responsabilidades das equipes para o controle.

Portanto, dispor os dados de uma auditoria do sistema da qualidade ao alcance dos olhos de qualquer colaborador faz com que o mesmo assuma para si a responsabilidade de manter esse sistema operando corretamente. A gestão visual apli- 
cada à auditoria do sistema da qualidade tornaria esse processo de conhecimento público (ou seja, de todos os colaboradores da empresa), ao invés de deixá-lo nas mãos de algumas poucas pessoas. Maiores oportunidades de acesso a informações dessa natureza seria uma forma de disseminar o sistema da qualidade dentro da organização, garantindo a sua manutenção e melhoria.

De acordo com Greif (1991), um sistema de gestão visual envolve as seguintes etapas:

a) visibilidade das anomalias: para que a interpretação do campo visual permita o reconhecimento rápido das anomalias que podem demandar respostas, permitindo que todos possam adotar o papel de observador. Através da disposição sistemática das deficiências, a gestão visual ajuda a desenvolver um sistema de observação coletivo;

b) desenvolvimento do sistema de resposta: esse sistema necessita transmitir um pronto feedback, dispondo mensagens próximas à mão e assegurar o compartilhamento das informações dentro do grupo de trabalho;

c) registro das anomalias: é importante criar uma forma de registrar as anomalias, para que as mesmas sejam analisadas posteriormente e as suas causas principais possam ser identificadas para a tomada de açôes corretivas. Esses registros das anomalias poderiam estar expostos em um grande mural para permitir ampla visualização.

\subsection{DIAGRAMA DE CAUSA E EFEITO COM ADIÇÃO DE CARTÓES}

O diagrama de causa e efeito com adição de cartôes (CEDAC - Cause and Effect Diagram with Addition of Cards) é uma modificação do diagrama de causa e efeito (ou diagrama de Ishikawa), uma ferramenta da gestão da qualidade bastante utilizada por grupos de solução de problemas.

Segundo Fukuda (1983), as diferenças entre o diagrama CEDAC e o diagrama de Ishikawa começam pela utilização no segundo de palavras simples escritas nos lugares apropriados das espinhas do diagrama, enquanto no primeiro são escritas sentenças curtas para expressar mais completamente o que é conhecido. A segunda grande diferença é a utilização no diagrama CEDAC de pequenos cartôes com o objetivo de facilitar e agilizar a coleta de idéias diretamente nas espinhas do diagrama. A utilização dos cartôes também facilita a revisão do diagrama.
O diagrama CEDAC é uma ferramenta que permite que os grupos de melhorias trabalhem com uma grande quantidade de informação qualitativa disponível na empresa e que não é, ou ainda não é, quantificável. Alguns trabalhos apresentam a utilização do CEDAC como uma ferramenta de apoio ao processo de melhoria contínua (SOHAL, TERZIOVSKI e ZUTSHI, 2003; LEEDE e LOOISE, 1999; CAPON, KAYE e WOOD, 1995; NOCI, 1995).

O diagrama CEDAC foi criado para lidar com situaçôes onde um método confiável para evitar a ocorrência de não-conformidades não foi estabelecido. Um padrão é estabelecido pela integração do conhecimento e da experiência de todos os envolvidos, desde os operadores até os gerentes, com o objetivo de prevenir a ocorrência de defeitos. Para a utilização do diagrama CEDAC não é preciso que os padrôes estejam formalizados de forma escrita, porém isso facilita não só a aplicação do diagrama como a própria transferência de informaçōes.

Se os padróes atuais permitem que problemas ou defeitos ocorram e não forem alterados, então o processo continuará a produzir defeitos. Neste caso, o emprego do diagrama CEDAC auxiliará no processo de estabelecer padrōes confiáveis para eliminar os defeitos graves causados pela inconsistência do padrão estabelecido.

\section{FERRAMENTA PROPOSTA DE APOIO À AUDITORIA INTERNA}

\subsection{CONSTRUÇÃO DO PAINEL DE AUDITORIA}

A ferramenta proposta, denominada de auditoria contínua, emprega os princípios da gestão visual e do diagrama CEDAC de forma a fortalecer o processo de manutenção e melhoria contínua de um sistema de garantia da qualidade com base na norma NBR ISO 9001. Trata-se de uma adaptação do diagrama CEDAC para ser aplicado como um instrumento de apoio na identificação de não-conformidades potenciais ou reais, aberto a participação de todos os envolvidos com cada um dos processos de uma dada organização. Ela mostra de forma clara e transparente todo o processo de implantação de uma ação corretiva ou preventiva, desde a identificação do problema até a verificação da eficácia da sua implantação. 
Como primeiro passo na implantação da ferramenta proposta, sugere-se a elaboração de um painel, que servirá como um local de encontro dos participantes na auditoria contínua. Para a construção desse painel é necessário levar em conta o espaço e as condições disponíveis para a instalação do mesmo em local acessível e de boa visualização por aqueles que tomarão parte no projeto. $\mathrm{O}$ ideal seria a instalação de um painel para cada processo do sistema de gestão da qualidade a ser monitorado por meio da auditoria contínua.

O painel pode ser feito em uma folha de papel branco, em formato A2 ou maior, com um diagrama de espinha de peixe desenhado na mesma para representar o lado das não-conformidades e o lado das ações corretivas ou preventivas, como mostra a figura 1.



Figura 1. Painel de auditoria contínua

O diagrama de espinha de peixe do painel terá ramificações de número igual ao número de requisitos da norma de referência, uma vez que cada ramificação representa um requisito aplicável do setor ou departamento onde o painel será fixado. $\mathrm{O}$ registro das não conformidades e das ações necessárias a serem implantadas para solucioná-las é feito através de cartões coloridos, que são colados no painel, como mostra a figura 2.

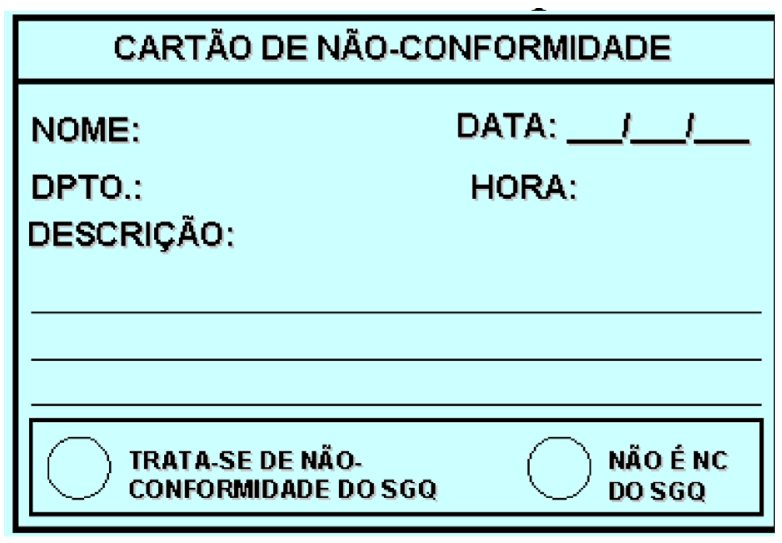

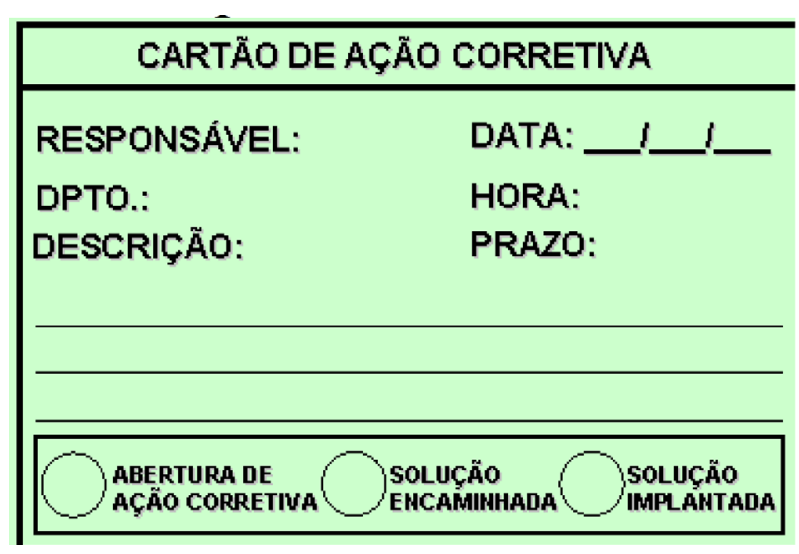

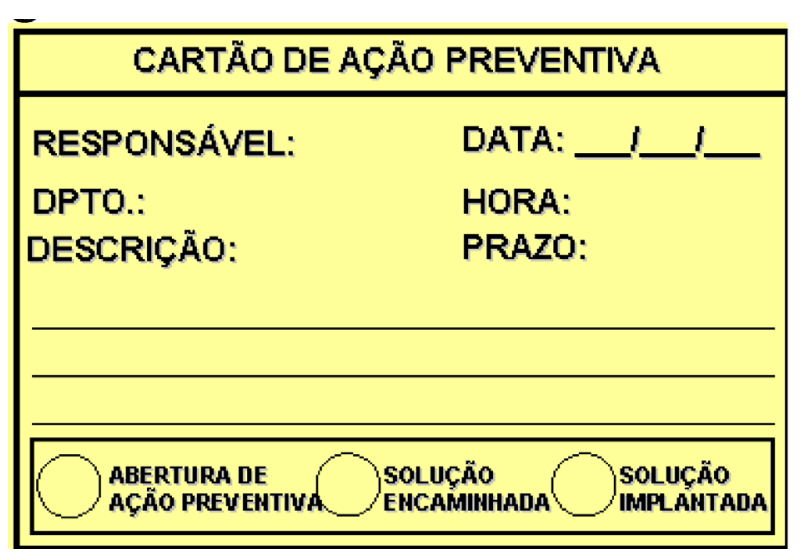

Figura 2. Cartóes usados no painel de auditoria contínua

Os cartões de não-conformidades servem para registrar as deficiências ou problemas potenciais (situações de risco) evidenciados no setor onde a auditoria contínua está sendo realizada. Esses cartôes são colados do lado esquerdo da ramificação do diagrama.

Os cartôes de ação corretiva servem para registrar as açôes corretivas necessárias para solucionar as não-conformidades evidenciadas durante a auditoria contínua. De forma análoga, os cartões de ação preventiva são utilizados para as não-conformidades potenciais. Esses cartôes são colados do lado direito da ramificação do diagrama, exatamente ao lado do cartão de não-conformidade, como mostra a figura 3.

Todos os funcionários envolvidos no sistema de gestão da qualidade de um dado setor podem participar da auditoria contínua, anotando no cartão de não-conformidade a deficiência evidenciada. Mesmo as pessoas de outros setores que interagem com o setor auditado podem participar.

Entretanto, como a participação é livre, alguns funcionários (por questôes de nível de escola- 


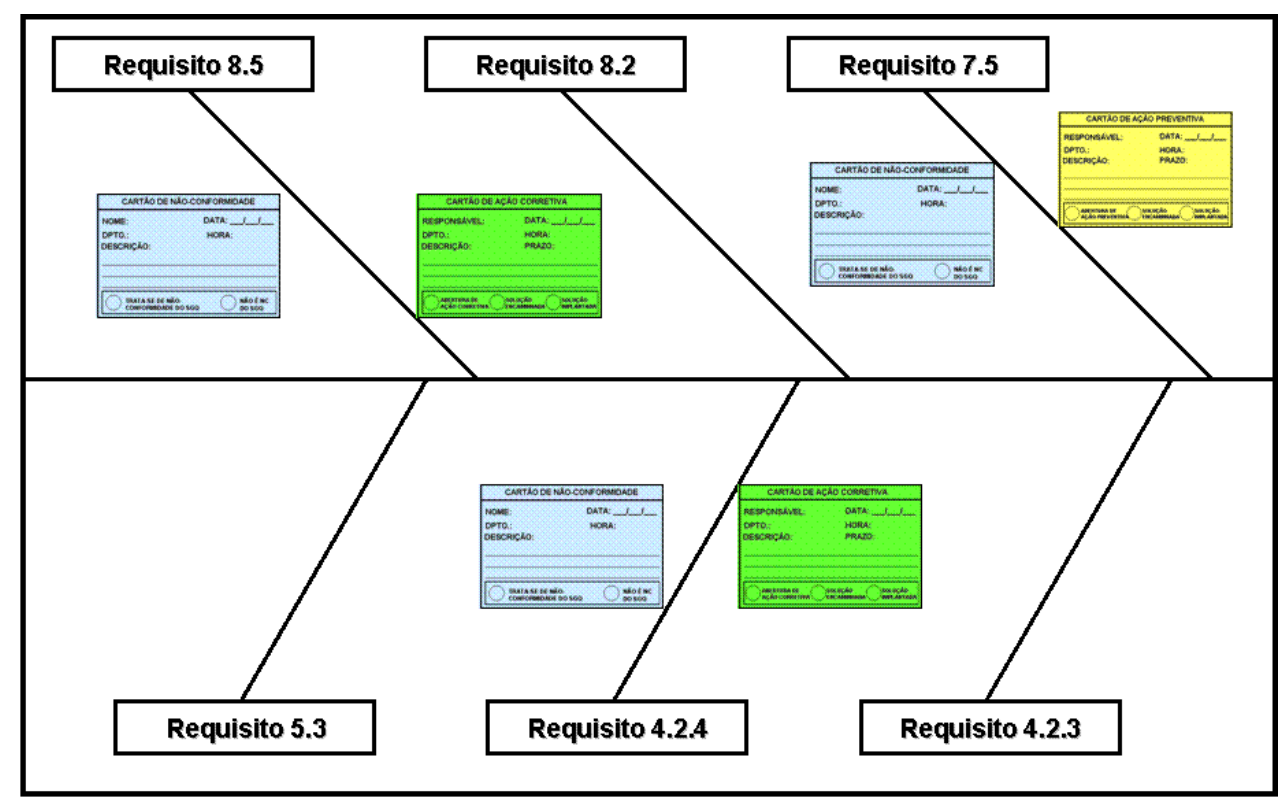

Figura 3. Posicionamento dos cartóes no painel

ridade, comprometimento com o sistema da qualidade ou outra razão qualquer) podem registrar problemas no cartão que não dizem respeito ao sistema da qualidade. Para que se possa fazer uma filtragem dos cartóes que realmente se referem ao sistema da qualidade, é fundamental que exista um líder para o projeto de auditoria contínua.

O líder do projeto, denominado de auditor de área, deve ser uma pessoa com treinamento adequado em auditorias da qualidade e que conheça a norma NBR ISO 9001 e o processo de trabalho do setor que trabalha. $\mathrm{O}$ auditor de área tem a tarefa de selecionar os cartôes que se referem ao sistema da qualidade daqueles que não se referem ao mesmo, analisar a causa da não-conformidade real ou potencial, descrever a ação corretiva ou preventiva necessária para solucionar as deficiências encontradas, acompanhar a implementação das mesmas e concluir a ação corretiva ou preventiva, após verificação da eficácia da mesma.

O participante que submete um cartão ao painel de auditoria deve colocar no mesmo o seu nome e o setor onde trabalha para facilitar a identificação no caso de necessidade de maiores detalhes sobre o conteúdo ou não entendimento de algum termo escrito. No caso do conteúdo de dois ou mais cartôes serem os mesmos, eles são colados sobrepostos no painel.

$\mathrm{O}$ auditor de área deve incentivar os funcionários a participar, orientando-os sobre como escrever as não-conformidades no cartão e, principalmente, conscientizando-os de que cada car- tão de não-conformidade que é colado no painel significa uma ação de aperfeiçoamento do sistema da qualidade.

Depois que o participante registra a deficiência observada no cartão de não-conformidade, o auditor de área separa as informaçōes, indicando na parte inferior do cartão (vide cartão de não-conformidade da figura 2) se o problema é relativo ao sistema da qualidade ou não. Dessa forma, também se contribui para que os funcionários se familiarizem com os problemas típicos do seu sistema da qualidade.

Se a deficiência apontada em um cartão de não-conformidade envolver a participação de pessoas de outros setores, é de responsabilidade do auditor de área ir até essas pessoas para descrever a ação corretiva ou preventiva adequada, assim como o prazo, para solucioná-la.

Para facilitar o acompanhamento e o andamento das ações corretivas e/ou preventivas a serem implantadas, existe, na parte inferior dos cartôes de ação corretiva e preventiva (vide cartôes na figura 2), um espaço reservado para informar: abertura de formulário de ação corretiva/preventiva, para indicar a necessidade de tomada de ação por um grupo de pessoas; solução encaminhada, para indicar que a ação necessária já está sendo tomada pelo grupo de pessoas nomeadas pelo auditor de área; solução implementada, para indicar que a ação necessária para eliminação da deficiência encontrada já foi implementada e se mostrou eficaz. 
No espaço reservado para essas informações, o auditor de área coloca uma etiqueta autocolante colorida ou marca um " $\mathrm{X}$ ", de acordo com $\mathrm{o}$ andamento das ações.

\subsection{TREINAMENTO DOS PARTICIPANTES}

A auditoria contínua parte do princípio de que todos os funcionários de uma dada área de trabalho podem atuar como se fossem auditores internos, apontando as não-conformidades existentes no sistema da qualidade. Para que a atuação desses funcionários como auditores seja proveitosa, é necessário que os mesmos recebam um treinamento adequado.

Este treinamento deve ser preparado de forma a atender a aplicação da auditoria contínua, uma vez os funcionários de nível operacional, principais participantes do processo, podem apresentar um baixo nível de escolaridade.

Neste caso, o treinamento para os participantes baseia-se nos principais requisitos da norma de aplicação (por exemplo, a norma NBR ISO 9001), com ênfase na busca por deficiências na documentação usada por eles. Esse treinamento pode ser feito durante as reunióes do responsável de cada setor com o seu grupo de trabalho, com cargas horárias menores. As deficiências relativas ao ambiente de trabalho dos funcionários poderiam constar nesse treinamento, como por exemplo, identificação de materiais, identificação de equipamentos de monitoramento e medição, identificação da situação de monitoramento e medição, ensaios dos lotes de produtos acabados ou em processo, validade da calibração dos equipamentos de medição etc.

Além desse treinamento nos conceitos da norma de aplicação é conveniente que se invista em treinamento comportamental, para incentivar os funcionários a participar do projeto de auditoria contínua e, principalmente, perder o receio ou a timidez natural que os mesmos apresentam no momento em que necessitam expressar a sua opinião.

\section{PESQUISA EMPÍRICA}

\subsection{DEFINIÇÃO DA UNIDADE DE ANÁLISE}

A empresa selecionada como unidade de análise foi uma empresa fabricante de produtos térmicos, líder do mercado nacional neste segmento até os dias de hoje. $\mathrm{Na}$ época da realização dessa pesquisa, a empresa estava implantando um sistema de gestão da qualidade e apresentava problemas com o alto índice de não-conformidades em suas auditorias internas. Contudo, o mais crítico é que havia uma baixa participação e interesse dos funcionários com o sistema de gestão da qualidade. Essas características identificadas na empresa na época da pesquisa motivaram a escolha da empresa como unidade de análise.

O método de pesquisa empregado foi a pesquisa-ação, pelo fato de existir uma alta interação do pesquisador com o objeto de estudo e a utilização da observação participante como principal técnica de coleta de dados. A aplicação da auditoria contínua na empresa foi realizada em dois momentos. No primeiro momento, antes da certificação, a investigação se deu no processo de gerenciamento da qualidade, coordenado pelo setor denominado Escritório de Gestão da Qualidade.

No segundo momento, após a certificação, a investigação se deu no processo de montagem de produtos térmicos, de forma a se criar uma oportunidade para a avaliação das diferenças a serem observadas na manutenção e melhoria de um sistema da qualidade já amadurecido.

\subsection{ESTRUTURA DA DOCUMENTAÇÃO DO SISTEMA DE GESTÃO DA QUALIDADE}

$\mathrm{Na}$ época da pesquisa, o sistema de gestão da qualidade foi implantado e certificado conforme os requisitos da norma NBR ISO 9001 (versão 1994). O sistema da qualidade consistia de um manual da qualidade e de outros documentos (procedimentos de sistema, receitas de trabalho, receitas de formulário e especificações técnicas) que o suportavam e explicavam os métodos para se obter a conformidade com os requisitos da política da qualidade.

\subsection{ESTUDO ANTES DA CERTIFICAÇÃO}

Esse estudo se deu durante o mês de Abril de 1997 na fase de implantação do sistema da qualidade para certificação pela norma NBR ISO 9001 (versão 1994), no Escritório de Gestão da Qualidade.

$\mathrm{Na}$ época, esse setor, responsável pelo controle dos documentos, enfrentava dificuldades 
para a implantação dos procedimentos pertinentes a esse requisito, uma vez que a imaturidade do sistema fazia com que os mesmos sofressem atualizações freqüentes, podendo induzir a erros de seu efetivo controle. O setor contava com um coordenador (efetivo indireto), com curso superior e capacitação em auditoria interna, e duas assistentes (efetivo direto), sendo que uma das assistentes possuía curso superior, enquanto a outra assistente estava em fase de conclusão do segundo grau. Em virtude desse cenário, o Escritório de Gestão da Qualidade ofereceu um ambiente propício para a avaliação da adequação da ferramenta proposta através da pesquisa-ação.

O objetivo da aplicação da auditoria contínua neste setor era atualizar as revisões dos procedimentos do sistema da qualidade para viabilizar o controle efetivo da documentação da qualidade da empresa. $\mathrm{O}$ pesquisador interagia fortemente com os colaboradores da empresa para o planejamento e realização desta fase da pesquisa.

Para isso foi desenhado um diagrama de espinha de peixe em um quadro de lousa branco. Cada espinha do diagrama correspondia a um procedimento, além de uma outra espinha para as não-conformidades das receitas de formulário (os únicos tipos de documentos que o setor possuía), como mostra a figura 5.

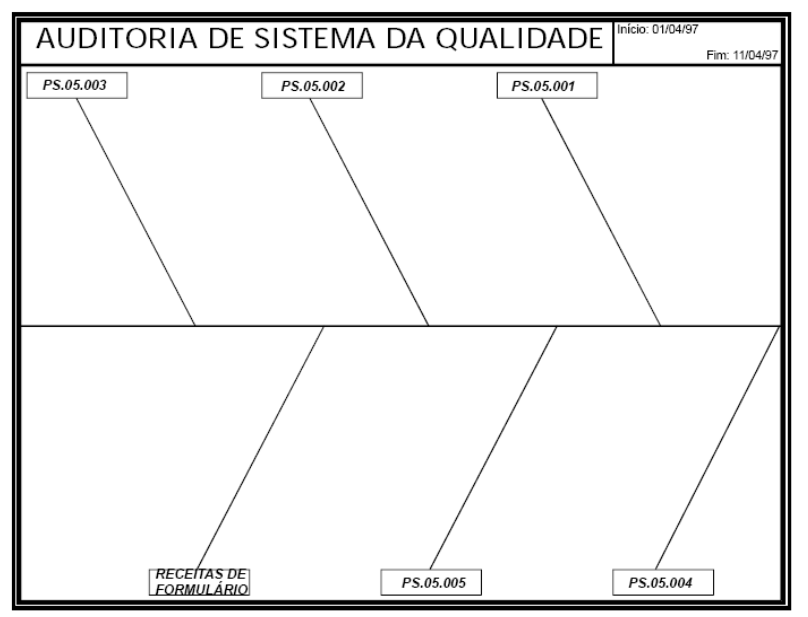

Figura 5. Painel de auditoria no Escritório de Gestão da Qualidade

$\mathrm{O}$ treinamento que foi dado às assistentes pelo coordenador (que era o pesquisador responsável pela realização da pesquisa) baseou-se na explicação do que se esperava da auditoria contínua e sobre a sua sistemática de aplicação. $\mathrm{O}$ coordenador (escolhido como auditor de área) e uma das assistentes integravam o grupo de auditores internos da empresa, tendo, portanto, treinamento adequado para conduzir o processo, além de conhecimento da norma de aplicação. A outra assistente, apesar de não ser auditora interna, também conhecia o sistema da qualidade e a norma de aplicação, por estar diretamente envolvida nos trabalhos do setor.

Além dos funcionários do setor analisado, outros funcionários que freqüentavam o mesmo (gerentes e supervisores de outros setores envolvidos na implantação do SGQ) também foram treinados na sistemática de aplicação da auditoria contínua para poderem participar da investigação.

Foram colocados à disposição dos participantes os cartões de não-conformidade e os cartões de ação corretiva e preventiva. À medida que as não-conformidades nos procedimentos do processo de controle de documentos eram evidenciadas, os cartões de não-conformidades eram fixados no painel da auditoria.

A participação, tanto dos funcionários do setor como de funcionários de outras áreas, foi grande, uma vez que o setor era o centro de padronização da empresa e era freqüentado por todos aqueles interessados na padronização das atividades da sua área de trabalho. Para cada cartão de não-conformidade que era fixado no painel, o auditor de área fixava um cartão de ação corretiva, com a descrição do plano de ação corretiva apropriada.

A cada ciclo de fixação de cartões era realizada uma reunião entre o pesquisador e os representantes do setor analisado, como uma estratégia para aperfeiçoar e implantar as adequações necessárias ao processo de pesquisa, bem como para replanejar os passos seguintes. Foram identificadas 20 não-conformidades nesta fase do estudo.

\subsection{ESTUDO APÓS A CERTIFICAÇÃO}

O estudo pós-certificação foi realizado no setor de montagem de produtos térmicos, que possuía na época três funcionários indiretos (um gerente e duas encarregadas) e 40 montadoras (efetivo direto), trabalhando em um único turno com quatro linhas.

Esse setor foi escolhido dentre todos os outros da empresa para a realização do estudo pós-certificação devido: ao grande número de documentos do sistema da qualidade; à grande 
variedade de requisitos (doze) da norma NBR ISO 9001 (versão 1994) pertinentes ao setor; uma funcionária (encarregada) com capacitação em auditoria interna da qualidade e pertencente ao quadro de auditores internos da empresa; número relativamente pequeno de funcionários no setor fabril.

O painel de auditoria foi colocado em local estratégico do setor de montagem, próximo a uma das saídas por onde todas as funcionárias passavam, em posição frontal para todas as quatro linhas de montagem, como mostra a figura 6 .

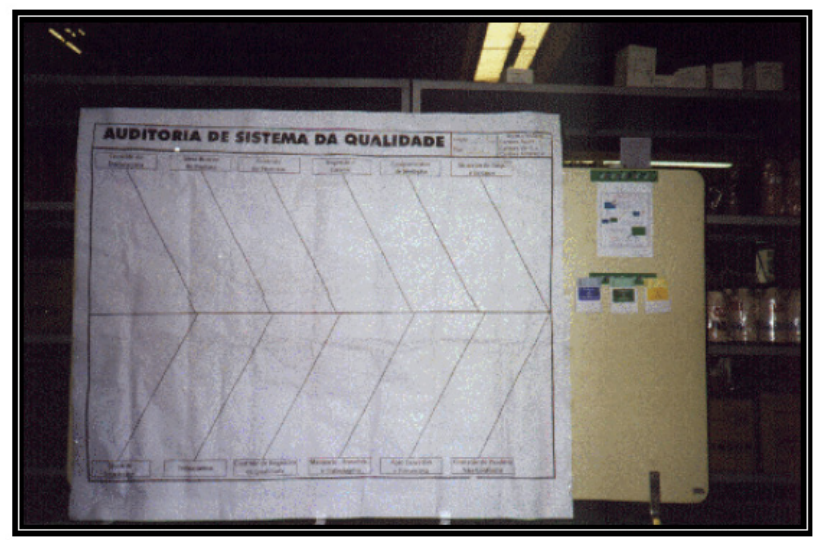

Figura 6. Painel de auditoria no setor de montagem

Ao lado do painel de auditoria foram colocados os cartões de não-conformidade, de ação corretiva e de ação preventiva. As regras de utilização dos cartôes também foram colocadas próximas ao painel.

Para auditor de área foi escolhida uma das encarregadas, por ela pertencer ao quadro de auditores internos da empresa. Além disso, ela possuía treinamento de interpretação de requisitos da norma NBR ISO 9001 e do seu processo de trabalho. Participaram do estudo de caso no setor de montagem o gerente da área, as funcionárias (montadoras de peças) e outras pessoas ligadas indiretamente ao setor como, por exemplo, o supervisor de manutenção, técnicos etc.

Antes do início da aplicação, todas as montadoras foram reunidas e treinadas na utilização da auditoria contínua para avaliação do sistema da qualidade. Toda vez que uma funcionária observava uma deficiência, ela chegava até o painel de auditoria e fixava um cartão de não-conformidade no mesmo. Assim que esse cartão era colocado no painel, a auditora de área fixava um cartão de ação corretiva apropriado. Se essa ação corretiva envolvesse pessoas de outros setores, a auditora de área era responsável por coletar junto a elas a ação apropriada, assim como acompanhar a implantação da mesma.

Algumas vezes as funcionárias confundiam o objetivo dos trabalhos e escreviam problemas não relacionados com o sistema da qualidade. Nestes casos, a auditora de área procurava a funcionária e explicava a ela o que era uma não-conformidade. Quando possível, alguns desses problemas eram resolvidos para não diminuir a motivação das funcionárias.

No final do tempo planejado para a aplicação da auditoria contínua, aproximadamente um mês, o painel de auditoria apresentou um total de 19 não-conformidades. Para despoluir o painel de auditoria e melhorar a visualização, à medida que as não-conformidades eram solucionadas, o cartão de não-conformidade e o cartão com a sua respectiva ação corretiva, eram colocados em um painel em separado (à direita na figura 7).

A cada ciclo de fixação de cartôes era realizada uma reunião entre o pesquisador e os representantes do setor analisado. Essas reunióes (ou seminários) foram importantes para aperfeiçoar a aplicação da auditoria contínua desde sua investigação inicial (antes da certificação) até a investigação do setor de montagem de produtos térmicos.

\section{DISCUSSÃO}

A realização dos estudos de adequação da ferramenta proposta permitiu observar que o processo de identificação das não-conformidades (reais ou potenciais) ganhou em agilidade, uma vez que as mesmas passaram a ser detectadas em tempo real, dando início à sistemática de análise da causa e tomada de ação corretiva ou preventiva.

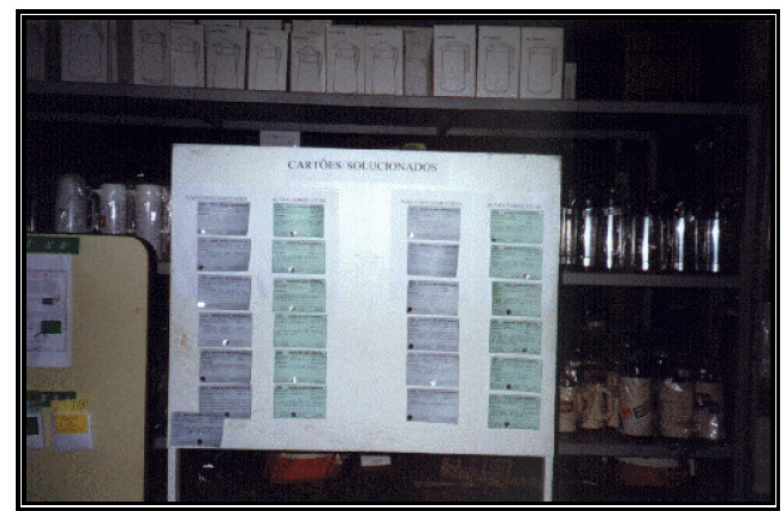






Figura 7. Painéis de auditoria após a aplicação no setor de montagem

O emprego da auditoria contínua possibilitou que o sistema da qualidade fosse avaliado em uma base contínua. Nas auditorias periódicas (de certificação ou manutenção do sistema de gestão), uma não-conformidade que não é detectada na amostragem selecionada pelo auditor, pode propagar os seus efeitos, causando danos consideráveis ao sistema da qualidade. Entretanto, a ferramenta proposta possibilita que um maior número de oportunidades de melhoria, ou de não-conformidades, sejam evidenciadas e corrigidas. Isso é possível pelo fato de que a ferramenta proposta monitora o sistema da qualidade diariamente, dentro do período de sua aplicação.

Observou-se que a participação do auditado na auditoria do sistema da qualidade aumentou. $\mathrm{O}$ auditado aponta as não-conformidades $\mathrm{e}$ cobra a correção das mesmas. $\mathrm{O}$ apelo visual desta ferramenta favorece essa participação.

Observou-se ainda durante o emprego da auditoria contínua que funcionários do nível operacional apontavam não-conformidades importantes através do cartão apropriado, mesmo não tendo treinamento formal de formação de auditores internos. Eles praticavam o autocontrole do processo pertinente ao sistema de gestão da qualidade sob sua responsabilidade.

$\mathrm{Na}$ auditoria convencional a independência dos auditores é condição necessária, mas mesmo na auditoria contínua com a avaliação sendo feita por funcionários envolvidos com seu próprio setor, as não-conformidades evidenciadas foram apontadas, deixando claro a conscientização dos participantes de que registrar e corrigir uma não-conformidade ou uma situação de risco potencial é uma oportunidade de melhorar o sistema da qualidade.
Como uma forma de verificar a adequação da auditoria contínua na redução do número de não-conformidades do sistema de gestão, foi realizada uma comparação das não-conformidades detectadas pela ferramenta proposta e por auditorias convencionais posteriores, como mostra a figura 8 .


Figura 8. Comparação de não-conformidades detectadas

Pode-se perceber uma sensível redução do número de não-conformidades nas auditorias convencionais posteriores ao emprego da auditoria contínua. Em ambos os casos, o número de não-conformidades apontadas referem-se apenas aos requisitos da norma NBR ISO 9001 aplicados. Os dados sugerem que a redução do número de não-conformidades apontadas nas auditorias convencionais foi obtida em virtude da auditoria contínua monitorar a manutenção/melhoria do sistema da qualidade ao longo do seu dia-a-dia, ao contrário da auditoria convencional, que atua periodicamente e através de uma amostra limitada.

Esses dados também apontam que o emprego da auditoria contínua pode contribuir na redução da freqüência das auditorias internas convencionais. Como a auditoria contínua mantém o sistema da qualidade sob monitoração constante, a necessidade de auditorias convencionais pode ser minimizada. Isso pode resultar em redução de 
custos operacionais para a empresa em virtude do menor número de vezes que seria necessária a alocação de tempo e de pessoas na preparação, planejamento e realização de auditorias internas para verificação da adequação do sistema de gestão da qualidade.

\section{CONCLUSÓES}

Considera-se que a presente pesquisa atingiu todos os seus objetivos previamente estabelecidos. Foi proposta uma ferramenta, denominada auditoria contínua, que contribuiu para auxiliar na manutenção e melhoria do sistema de gestão da qualidade analisado, como mostraram os dados coletados na empresa estudada. Ela proporcionou instrumentos para registro das deficiências do sistema da qualidade em tempo real, aumentou a participação dos colaboradores na avaliação e melhoria do sistema da qualidade e contribuiu na redução do número de não-conformidades nos requisitos analisados durante a investigação, minimizando algumas das principais limitações do processo convencional das auditorias. Considera-se que esta ferramenta possa ser útil para empresas que desejem mudar o paradigma da realização das suas auditorias da qualidade, visando socializar a informação a respeito de seu sistema para todos os participantes, melhorando o entendimento e a participação efetiva no processo de melhoria contínua.

Metodologicamente, a pesquisa proporcionou a oportunidade de se apresentar uma pesquisa-ação retrospectiva cuja utilização não é muito comum, apesar de aceita por pesquisadores das ciências sociais e da gestão de operações. Ressalta-se que este tipo de pesquisa retrospectiva só é possível quando a pesquisa original também é realizada por meio de uma pesquisa científica planejada. Caso contrário, o rigor científico exigido não poderá ser obtido a posteriori. Essa é uma condição necessária e imprescindível para a realização deste tipo de pesquisa.

Além disso, o presente trabalho ofereceu uma contribuição científica que foi a proposta de uma ferramenta de apelo visual para ser empregada como apoio na melhoria contínua dos sistemas de gestão da qualidade e uma contribuição prática, que foi o aumento da participação dos funcionários nas auditorias da empresa estudada, como requer o método da pesquisa-ação.
Finalmente, a ferramenta proposta mostrou ser um sistema de gestão visual para monitoramento do sistema de gestão da qualidade, pois envolveu todas as etapas sugeridas por Greif (1991), ou seja, propiciou a visibilidade das não-conformidades, criando um sistema de monitoramento coletivo do sistema de gestão da qualidade; os cartōes de ações corretivas e preventivas tornaram-se um sistema de resposta rápida e eficaz, deixando as ações necessárias para correção ou prevenção de uma situação de risco real ou potencial e diminuindo o tempo entre a ocorrência do problema e a análise do mesmo; todas as não-conformidades evidenciadas eram registradas nos cartões de não-conformidades, permitindo que a análise da causa e a tomada da ação necessária ocorresse rapidamente, por estarem dispostas de forma a permitir sua ampla visualização, definindo responsabilidades pelas mesmas.

A ferramenta proposta neste trabalho não tem a pretensão de substituir o processo convencional de auditorias, mas sim oferecer um instrumento participativo, de socialização da informação, para apoiar esse processo.

\section{REFERÊNCIAS}

ASSOCIAÇÃO BRASILEIRA DE NORMAS TÉCNICAS. Norma ISO 9000. Sistemas de gestão da qualidade: Fundamentos e vocabulário. Rio de Janeiro: ABNT, 2005.

BALLANTYNE, D. Action research reviewed: a market-oriented approach. European Journal of Marketing, v. 38, n. 3/4, p. 321-337, 2004.

BALLANTYNE, D. A relationship mediated theory of internal marketing. European Journal of Marketing, v. 37, n. 9, p. 1242-1260, 2003.

BALLANTYNE, D. Internal relationship marketing: a strategy for knowledge renewal. International Journal of Bank Marketing, v. 18, n. 6, p. 274-286, 2000.

CAPON, N.; KAYE, M. M.; WOOD, M. Measuring the success of a TQM programme. International Journal of Quality \& Reliability Management, v. 12, n. 8, p. 8-22, 1995.

COUGHLAN, P. e COGHLAN, D. Action research. Action research for operations manage- 
ment. International Journal of Operations \& Production Management, v. 22, n. 2, p. 220240, 2002.

DURMUSOGLU, M. B.; KULAK, O. A methodology for the design of office cells using axiomatic design principles. Omega - The International Journal of Management Science, v. 36, p. 633-652, 2008.

FILIPPINI, R. Operations management research: some reflections on evolution, models and empirical studies in OM. International Journal of Operations \& Production Management, v. 17, n. 7, p. 655-670, 1997.

FUKUDA, R. Managerial engineering: techniques for improving quality and productivity in the workplace. Productivity Press, Inc., 1983.

GREIF, M. The visual factory. Building participation through shared information. Massachusetts: Productivity Press, Inc. Cambridge, 1991.

HALL, R. W. Attaining manufacturing excellence - Just in Time, Total Quality, Total People Involvement. Illinois: Dow Jones-Irwin, Homewood, 1987.

KARAPETROVIC, S.; WILLBORN, W. Quality assurance and effectiveness of quality audit. International Journal of Quality and Reliability Management, v. 17, n. 6, p. 679-703, 2000.

KAZILIÛNAS, A. Problems of auditing using quality management systems for sustainable development of organizations. Technological and Economic Development of Economy, v. 14, n. 1, p. 64-75, 2008.

LEEDE, J. de; LOOISE, J. K. Continuous improvement and the mini-company concept. International Journal of Operations \& Production Management, v. 19, n. 11, p. 1188-1202, 1999.

MESTRE, M.; STAINER, A.; STAINER, L.; STROM, B. Visual communications - the Japanese experience. Corporate Communications: an International Journal, v. 5, n. 1, p. 34-41, 1999.
MILLS, C. A. A auditoria da qualidade uma ferramenta para avaliação constante $e$ sistemática da manutenção da qualidade. São Paulo: Makron Books, 1994.

NOCI, G. Accounting and non-accounting measures of quality-based performances in small firms. International Journal of Operations \& Production Management, v. 15, n. 7, p. 78-105, 1995.

O'HANLON, T. Auditoria da qualidade: com base na ISO 9001:2000: conformidade agregando valor. Trad.: Gilberto Ferreira de Sampaio. São Paulo: Saraiva, 2006.

PAXTON, R.; WHITTY, P.; ZAATAR, A.; FAIRBAIRN, A.; LOTHIAN, J. Research, audit and quality improvement. International Journal of Health Care Quality Assurance, v. 19 n. 1, p. 105-111, 2006.

RANKY, P. G. Eighteen "monozukuri-focused” assembly line design and visual factory management principles with DENSO industrial examples. Assembly Automation, v. 27, n. 1, p. 1216, 2007.

SOHAL, A. S.; TERZIOVSKI, M.; ZUTSHI, A. Team-based strategy at Varian Australia: a case study. Technovation, v. 23, p. 349-357, 2003.

SOUZA, L. P.; FARIA NETO, A.; MUNIZ, J. Análise crítica do processo de auditoria de sistema de gestão da qualidade no setor aeroespacial. Anais do XXIX Encontro Nacional de Engenharia de Produção (ENEGEP), Salvador/BA, Brasil, 2009.

SULLIVAN, L. P. The seven stages in companywide quality control. Quality Progress, May, 1986.

TERZIOVSKI, M.; POWER, D.; SOHAL, A. S. From conformance to performance and continuous improvement using the ISO 9000 quality system standard. International Journal of Business Performance Management, v. 4, n. 1, p.1-23, 2002.

THIOLLENT, M. Metodologia da pesquisaação. São Paulo: Cortez Editora, 7a. ed., 1996. 